\title{
Indigofera oblongifolia mitigates lead-acetate- induced kidney damage and apoptosis in a rat model
}

\author{
Mohamed A Dkhil ${ }^{1,2}$ \\ Mohamed S Al-Khalifa' \\ Saleh AI-Quraishy' \\ Rafat Zrieq ${ }^{3}$ \\ Ahmed Esmat Abdel \\ Moneim² \\ 'Department of Zoology, College of \\ Science, King Saud University, Riyadh, \\ Saudi Arabia; ${ }^{2}$ Department of Zoology \\ and Entomology, Faculty of Science, \\ Helwan University, Cairo, Egypt; \\ ${ }^{3}$ Department of Clinical Laboratory \\ Sciences, College of Applied Medical \\ Sciences, University of Hail, Hail, \\ Saudi Arabia
}

This article was published in the following Dove Press journal:

Drug Design, Development and Therapy

2 June 2016

Number of times this article has been viewed

\begin{abstract}
This study was conducted to appraise the protective effect of Indigofera oblongifolia leaf extract on lead acetate ( $\mathrm{PbAc}$ )-induced nephrotoxicity in rats. PbAc was intraperitoneally injected at a dose of $20 \mathrm{mg} / \mathrm{kg}$ body weight for 5 days, either alone or together with the methanol extract of I. oblongifolia $(100 \mathrm{mg} / \mathrm{kg})$. Kidney lead $(\mathrm{Pb})$ concentration; oxidative stress markers including lipid peroxidation, nitrite/nitrate, and glutathione (GSH); and antioxidant enzyme activities, namely superoxide dismutase, catalase, GSH peroxidase, and GSH reductase were all determined. The $\mathrm{PbAc}$ injection elicited a marked elevation in $\mathrm{Pb}$ concentration, lipid peroxidation, and nitrite/nitrate, with a concomitant depletion in GSH content compared with the control and a remarkable decrease in antioxidant enzymes. Oxidant/antioxidant imbalance, $\mathrm{Pb}$ accumulation, and histological changes in the kidneys were successfully prevented by the pre-administration of I. oblongifolia extract. In addition, the elevated expression of proapoptotic protein, Bax, in the kidneys of the PbAc-injected rats was reduced as a result of I. oblongifolia pre-administration, while the hitherto reduced expression of the anti-apoptotic protein Bcl-2 was elevated. Based on the current findings, it can be concluded that I. oblongifolia successfully minimizes the deleterious effects in kidney function and histological coherence associated with nephrotoxicity by strengthening the antioxidant defense system, suppressing oxidative stress, and mitigating apoptosis.
\end{abstract}

Keywords: lead acetate, Indigofera oblongifolia, oxidative stress, apoptosis, kidney

\section{Introduction}

Lead $(\mathrm{Pb})$ is a very widespread environmental pollutant that has produced a wide range of devastating toxic effects that are known to have a negative influence on some organs and to induce a wide range of biochemical, physiological, and behavioral dysfunctions. ${ }^{1,2}$ The kidney is especially susceptible to the damaging effects of $\mathrm{Pb}$ due to its major role in the excretion of $\mathrm{Pb}$ from the body. ${ }^{2,3}$ Lead is removed readily by proximal tubule cells, where it damages mitochondria, suppresses mitochondrial function, and alters the physical absorptive activities of the cell, causing renal tubular damage and renal failure. Furthermore, the long-term $\mathrm{Pb}$ exposure can result in the development of chronic $\mathrm{Pb}$ nephropathy. ${ }^{4}$ Like other heavy metals, $\mathrm{Pb}$ has been reported to generate reactive oxygen species (ROS), thereby inducing oxidative injury to the kidney. ${ }^{5}$

Exposure to $\mathrm{Pb}^{2+}$ via different routes has been found to enhance lipid peroxidation (LPO) in kidney and deplete glutathione (GSH). Consistently, Pb has been found to inhibit sulfhydryl-dependent enzymes, interfere with metals that are important for antioxidant enzyme activities, and/or increase the vulnerability of cells to oxidative attack by impairing the integrity and fatty acid composition of renal cell membranes. ${ }^{6,7}$

\section{Moneim}

Department of Zoology and Entomology, Faculty of Science, Helwan University, Cairo II795, Egypt

Tel +2 II 53322079

Email aest1977@hotmail.com
Drug Design, Development and Therapy 2016:10 1847-1856

(c) (1) (8) ๑ 2016 Dkhil et al. This work is published and licensed by Dove Medical Press Limited. The full terms of this license are available at https:/www.dovepress.com/terms.php cc. hereby accept the Terms. Non-commercial uses of the work are permitted without any further permission from Dove Medical Press Limited, provided the work is properly attributed. For permision for commercial use of this work, please see paragraphs 4.2 and 5 of our Terms (https://www.doveperess. com/terms.php). 
Herbal and natural products possess antioxidant properties, and antioxidant molecules of plant origin have been widely investigated as scavengers of free radicals and suppressors of LPO. In this regard, numerous studies have exhibited the antioxidant activities of several natural products against many toxic metals. ${ }^{5,8}$ Indigofera oblongifolia is a perennial shrub belonging to the Fabaceae family and has a large geographical distribution, including Saudi Arabia. This plant contains a novel alkylated xanthene called indigin in addition to indigoferic acid, the fatty acid ester of $p$-hydroxy (E)-cinnamic acid, $\beta$-sitosterol, and 3 -hydroxybenzoic acid. ${ }^{9}$ I. oblongifolia has been shown to protect hepatocytes from carbon tetrachloride-induced hepatotoxicity through its strong capacity to inhibit oxidative stress-induced membrane lipids, nuclear DNA, and protein oxidation. ${ }^{10}$

To our knowledge, no other studies are available on the protective effect of I. oblongifolia leaf extract (IOLE) on $\mathrm{Pb}$-induced nephrotoxicity in rats. In view of this, the current study was conducted to elucidate whether IOLE, when preadministered to lead acetate $(\mathrm{PbAc})$, can ameliorate oxidative stress-induced nephrotoxicity.

\section{Materials and methods}

\section{Chemicals and animals}

Lead(II) acetate trihydrate $\left(\mathrm{Pb}\left(\mathrm{CH}_{3} \mathrm{CO}_{2}\right)_{2} \cdot 3 \mathrm{H}_{2} \mathrm{O}\right.$; CAS Number 6080-56-4), nitro blue tetrazolium, $N$-(1-naphthyl) ethylenediamine dihydrochloride, and $\mathrm{Tris}-\mathrm{HCl}$ were obtained from Sigma-Aldrich Co. (St Louis, MO, USA). 2-Thiobarbituric acid and trichloroacetic acid were obtained from Merck Millipore (Billerica, MA, USA). The chemicals and reagents used were all of analytical grade.

In this study, we used adult male Wistar albino rats, which were 150-180 $\mathrm{g}$ in weight. The animals were purchased from the animal facility of the Holding Company for Biological Products and Vaccines (Vacsera, Cairo, Egypt). The rats were maintained on a standard commercial pelleted diet in an air-conditioned animal house at $22^{\circ} \mathrm{C}-25^{\circ} \mathrm{C}$. All experiments were conducted according to the ethical standards approved by the Institutional Animal Ethics Committee guidelines for animal care and use, Helwan University, Egypt.

\section{Preparation of $I$. oblongifolia extract}

I. oblongifolia leaves were obtained from Jazan city located in the southwest of Saudi Arabia. The plant material was authenticated by Doctor Pandalayil (Botany Department, College of Science, King Saud University). The plant leaves were air dried at a room temperature and ground into powder using a pulveriser. One hundred grams of powdered leaves were extracted with $70 \%$ methanol at $4^{\circ} \mathrm{C}$ for 24 hours by occasional mixing. The leaf extract was filtered and then evaporated until it was dry in a vacuum evaporator (Heidolph, Schwabach, Germany). Residues were dissolved in water before use in the experimental study.

\section{Chromatography analysis}

Analysis was performed using a high-performance liquid chromatography (HPLC) system (Waters Corporation, Milford, MA, USA). The HPLC system was equipped with a 717 automatic injector and provided with a column oven, two pumps (model 510), a diode array detector (model 2996), and Millennium software v.3.1 data module (Waters Corporation, Milford, MA, USA). The separation was executed on a reversed-phase Nucleosil $120 \mathrm{C}_{18}(25 \mathrm{~cm} \times 4.6 \mathrm{~mm}, 3 \mu \mathrm{m})$ column obtained from Teknokroma (Barcelona, Spain). The mobile phase composed of water and methanol with the gradient elution system at a flow rate of $0.8 \mathrm{~mL} / \mathrm{min}$. The injection volume was $20 \mu \mathrm{L}$ after filtration through a $0.22 \mu \mathrm{m}$ polyvinylidene difluoride membrane. The detection of ultraviolet (UV) wavelength was set at $280 \mathrm{~nm}$. The column temperature was set at $25^{\circ} \mathrm{C}$.

\section{Experimental design}

Rats were randomly allocated into four groups of seven animals per group. Rats in the first group (group I) were orally gavaged with $0.3 \mathrm{~mL}$ saline, then, after 1 hour, $100 \mu \mathrm{L}$ of saline was injected intraperitoneally (IP). Groups II ( $\mathrm{PbAc}$ group) and IV (IOLE + PbAc group) received a daily IP injection of $\mathrm{PbAc}(20 \mathrm{mg} / \mathrm{kg}$ body weight [bwt]), and groups III (IOLE group) and IV were orally treated with IOLE $(100 \mathrm{mg} / \mathrm{kg}$ bwt). Animals were inoculated with their respective doses daily for 5 days. In the IOLE + PbAc group, the treatment of IOLE was given before, about an hour, PbAc. IOLE was orally administered at a dose of $100 \mathrm{mg} / \mathrm{kg}$ bwt according to Lubbad et al, ${ }^{11}$ while PbAc was IP injected with an acute toxic dose of $20 \mathrm{mg} / \mathrm{kg}$ bwt, according to Abdel Moneim. ${ }^{12}$

Twenty-four hours after administering the last dose, blood was collected from all the animals by cardiac puncture. Blood serum was separated by centrifugation at $1,000 \times g$ for 15 minutes and used for the kidney function parameters, while the rats were sacrificed by means of mild ether anesthesia. Rat kidneys were removed, weighed, and washed twice in ice-cold $50 \mathrm{mM}$ Tris- $\mathrm{HCl}, \mathrm{pH}$ 7.4. The kidneys were homogenized in ten volumes of ice-cold medium of $50 \mathrm{mM}$ Tris- $\mathrm{HCl}$ ( $\mathrm{pH}$ 7.4). Kidney homogenates were centrifuged at $1,000 \times g$ for 10 minutes at $4^{\circ} \mathrm{C}$. The supernatants were used for various biochemical studies. The protein level of the homogenates was assessed using Lowry et al's method. ${ }^{13}$ 


\section{$\mathrm{Pb}$ concentration in the kidney}

$\mathrm{The} \mathrm{Pb}$ concentration in the kidney was determined following the method set out by Abdel Moneim. ${ }^{12}$ Briefly, kidney tissue was dried and then combusted for 24 hours at $450^{\circ} \mathrm{C}$. Digested samples were analyzed at $283.3 \mathrm{~nm}$ using a flame atomic absorption spectrophotometer (3100; PerkinElmer Inc., Waltham, MA, USA). $\mathrm{Pb}$ accumulation in the kidney tissue was determined as microgram per gram wet weight.

\section{Changes in kidney index of rats}

The relative kidney weight was calculated using the following formula:

$$
\frac{\text { Left kidney weight }}{\text { Body weight }} \times 100
$$

\section{Kidney oxidative damage}

Kidney homogenates were subjected to a thiobarbituric acid reaction to determine LPO levels, which were expressed in terms of the amount of malondialdehyde (MDA) formed. ${ }^{14}$ Nitrite/nitrate (nitric oxide, NO) and GSH were assayed using the methods of Sun et al ${ }^{15}$ and Rahman et al, ${ }^{16}$ respectively.

\section{Antioxidant status}

Kidney homogenates were used for the determination of superoxide dismutase (SOD) according to Fisher et al, ${ }^{17}$ catalase (CAT) as described by Aebi, ${ }^{18}$ and GSH peroxidase (GPx) and GSH reductase (GR) following De Vega et al. ${ }^{19}$

\section{Quantitative real-time polymerase chain reaction}

After isolating the total kidney RNA, the RNA was purified using an RNeasy Plus Minikit (Qiagen NV, Venlo, the Netherlands). cDNA synthesis was carried out using the RevertAid ${ }^{\mathrm{TM}} \mathrm{H}$ Minus Reverse Transcriptase (Thermo Fisher Scientific, Waltham, MA, USA). The cDNA samples were run in triplicate for real-time polymerase chain reaction (PCR) analysis. Real-time PCR reactions were performed using Power SYBR ${ }^{\circledR}$ Green (Thermo Fisher Scientific) on the Applied Biosystems 7500 system (Thermo Fisher Scientific). Relative values of gene expression were normalized to $\beta$-actin. The PCR primers for the following genes were synthesized by Jena Bioscience GmbH (Jena, Germany): $\beta$-actin (accession number: NM_031144.3; forward: 5'-GGCATCCTGACCCTGAAGTA-3'; reverse: 5'-GGGGTGTTGAAGGTCTCAAA-3'), SOD2 (manganese-dependent SOD; accession number: NM_001270850.1; forward: 5'-AGCTGCACCACAGCAA GCAC-3'; reverse: 5'-TCCACCACCCTTAGGGCTCA-3'), CAT (accession number: NM_012520.2; forward:
5' - T C C GGGA T C T T T T T A A C GC C A T T G - 3'; reverse: 5'-TCGAGCACGGTAGGGACAGTTCAC3'), GPx (accession number: NM_017006.2; forward: 5'-CGGTTTCCCGTGCAATCAGT-3'; reverse: 5'-ACACC GGGGACCAAATGATG-3'), B-cell lymphoma 2 (Bcl-2; accession number: NM_016993.1; forward: 5'-CTGGTGGACAACATCGCTCTG-3'; reverse: 5'-GGTCTGCTGACCTCACTTGTG-3'), and Bcl-2like protein 4 (Bax; accession number: NM_017059.2; forward: 5'-GGCGAATTGGCGATGAACTG-3'; reverse: 5'-ATGGTTCTGATCAGCTCGGG-3').

\section{Histological examination}

The right kidney was fixed in $10 \%$ neutral buffered formaldehyde for 24 hours, dehydrated in alcohol, cleared in xylene, and mounted in molten paraffin wax. The paraffinembedded tissues were sectioned at 4-5 $\mu \mathrm{m}$ and stained with hematoxylin and eosin. Sections were examined using a light microscope (Eclipse E200-LED; Nikon Corporation, Tokyo, Japan).

\section{Caspase- 3 in kidney tissue}

Kidney tissue samples were fixed in neutral buffered formalin (10\%), embedded in paraffin, and cut into $4 \mu \mathrm{m}$ thick sections. Immunocytochemical reactions were performed using the peroxidase/anti-peroxidase method. Nonspecific peroxidase reactions were blocked with methanol containing $0.1 \% \mathrm{H}_{2} \mathrm{O}_{2}$, and the sections were also incubated with normal goat serum to avoid nonspecific reactions with the background once the samples were incubated with the specific antibody against caspase-3 (rabbit polyclonal, dilution, 1:2,000, category no: ab2302; Abcam, Cambridge, MA, USA). Tissue sections were then washed with phosphate buffer and incubated with a secondary antibody (1:2,000; Sigma-Aldrich Co.), before being washed in phosphate buffer again and, finally, incubated with the peroxidase/anti-peroxidase complex (dilution, 1:200). The peroxidase reaction was carried out using a solution of 3,3'diaminobenzidine tetrahydrochloride containing $0.01 \% \mathrm{H}_{2} \mathrm{O}_{2}$ in Tris- $\mathrm{HCl}$ buffer (0.05 M, pH 7.6). After being washed in phosphate-buffered saline, tissues were counterstained with hematoxylin and observed under a light microscope.

\section{Statistical analysis}

All results were expressed as mean \pm standard error of the mean. Data for multiple variable comparisons were analyzed by one-way ANOVA. For the comparison of significance between groups, Duncan's test was used as a post hoc test. The acceptable level of significance was established at $P<0.05$. 


\section{Results}

Phenolic profiles evaluated at $280 \mathrm{~nm}$ for the IOLE evaluation are shown in Figure 1. The chromatogram shows the presence of many peaks with retention times between 4 minutes and 65 minutes. Based on the UV-visible spectral data and their retention time, the IOLE has UV band characteristic for phenolic compounds, possibly quercetin, kaempferol, cinnamic acid, vanillic acid, flavonol, or flavone derivatives.

At the end of the course, rats injected with $\mathrm{PbAc}$ alone had a nonsignificant decline in their final body weight with a significant $(P<0.05)$ elevation in the relative kidney weight compared with the control animals. The pre-administration of IOLE (group IV), however, significantly ameliorated all these parameters to the control levels (Table 1).

The data illustrated in Figure 2 shows that $\mathrm{Pb}^{2+}$ concentration in kidney tissue was significantly raised in the $\mathrm{PbAc}$ group compared with the control rats $(P<0.05)$. Preadministration of IOLE, however, significantly decreased the $\mathrm{Pb}^{2+}$ concentration in the kidneys of the IOLE $+\mathrm{PbAc}$ group compared with the PbAc-treated group.

Rats subjected to $\mathrm{Pb}$-induced oxidative stress exhibited severe kidney injury, as evidenced by obvious increases in the levels of serum uric acid, urea, and creatinine compared with the control rats (Figure 3). Treatment with $100 \mathrm{mg} / \mathrm{kg}$ of IOLE, however, significantly reversed this elevation $(P<0.05)$.

$\mathrm{PbAc}$ injection significantly elevated the production of MDA and NO generation in the kidney $(P<0.05)$. Meanwhile, an obvious decrease in the GSH content in the kidney was found when compared with the control group $(P<0.05)$. The results also illustrated that $\mathrm{PbAc}$ injection inhibited the activities of SOD and CAT $(P<0.05)$, and there was also an evident (although nonsignificant) inhibition in GR and GPx activities. Interestingly, treatment with $100 \mathrm{mg} / \mathrm{kg}$ IOLE significantly attenuated the production of MDA and NO generation, as well as reversed the depletion of GSH content induced by $\mathrm{PbAc}$ injection in the kidney $(P<0.05)$. In addition, the current study reveals that treatment with $100 \mathrm{mg} / \mathrm{kg}$ IOLE elevated SOD, CAT, and GPx activities $(P<0.05)$, although it failed to change the GR activity significantly compared with the control group (Table 2). Consistent with the biochemical analysis, the quantitative PCR results showed that the mRNA of SOD2, $\mathrm{CAT}$, and GPx were downregulated after PbAc injection but that IOLE was able to upregulate these genes (Figure 4).

Rats intoxicated with $\mathrm{PbAc}$ revealed moderate-to-severe inflammation and extensive degeneration as indicated by the mononuclear cell infiltrations, cytoplasmic vacuolation, and congested glomeruli (Figure 5). In addition, serious apoptosis and necrosis were observed in the section as indicated by the presence of karyomegaly and hyperchromatic nuclei in the tubular epithelial cells of the renal tissue. Treatment of rats with IOLE largely improved these $\mathrm{Pb}$-induced histopathological alternations in the kidney tissue (Figure 5).

To investigate whether the observed protective effects of IOLE were related to the antiapoptotic property of IOLE, the expression levels of Bcl-2 and Bax in the kidney were determined. The results indicated that the expression of Bcl-2 mRNA was downregulated significantly (Figure 6), and the expression of Bax mRNA was upregulated in the $\mathrm{PbAc}$ treated group $(P<0.05)$. However, these effects were reversed in rats which received $100 \mathrm{mg} / \mathrm{kg}$ of IOLE prior to PbAc $(P<0.05$; Figure 6).

An immunohistochemical examination was performed to confirm the apoptosis induced in the kidney. In the $\mathrm{PbAc}$-injected group, the expression of the apoptotic protein, caspase-3, was increased (Figure 7). The preadministration of IOLE to rats exhibited improvement represented by the expression of caspase- 3 in the cytoplasm was largely decreased compared with that in the $\mathrm{PbAc}$ rats (Figure 7).

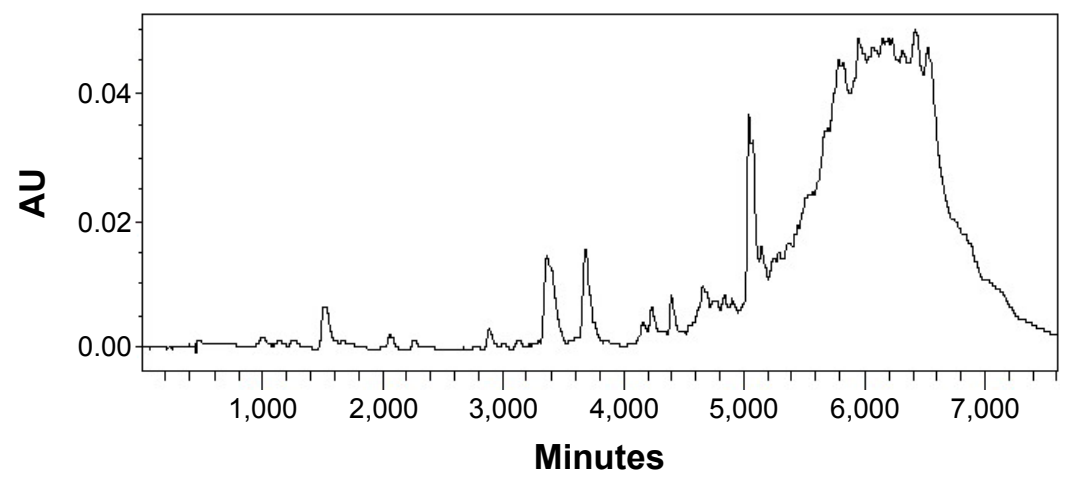

Figure I HPLC-DAD phenolic profiles for the IOLE recorded at $280 \mathrm{~nm}$.

Abbreviations: AU, arbitrary unit; DAD, diode array detector; HPLC, high-performance liquid chromatography; IOLE, Indigofera oblongifolia leaves extract. 
Table I Final body and relative kidney weights in each group

\begin{tabular}{lllll}
\hline Parameters & Control group & PbAc group & IOLE group & IOLE + PbAc group \\
\hline Final body weight $(\mathrm{g})$ & $173.4 \pm 6.3$ & $161.1 \pm 3.8$ & $175.3 \pm 4.7$ & $169.2 \pm 5.8^{\mathrm{b}}$ \\
Relative kidney weight $(\mathrm{g} / 100 \mathrm{~g}$ bwt) & $0.87 \pm 0.10$ & $1.18 \pm 0.17^{\mathrm{a}}$ & $0.97 \pm 0.11$ & $1.01 \pm 0.08^{\mathrm{b}}$ \\
\hline
\end{tabular}

Notes: Values are given as mean \pm SEM $(n=7)$. ${ }^{a}<<0.05$, significant change with respect to control; ${ }^{b}<0.05$, significant change with respect to PbAc for Duncan's post hoc test.

Abbreviations: bwt, body weight; IOLE, Indigofera oblongifolia leaf extract; PbAc, lead acetate; SEM, standard error of the mean.

\section{Discussion}

It is worth noting that the kidney is the first target organ of $\mathrm{Pb}$ toxicity because of its ability to reabsorb and accumulate $\mathrm{Pb} .{ }^{20}$ Accordingly, it has been reported that both acute and chronic intoxication with $\mathrm{Pb}$ causes nephrotoxicity, In addition, a previous study revealed that $\mathrm{Pb}$ inhibits sulfhydryl-dependent enzymes by forming high-affinity multidentate complexes with thiol $(-\mathrm{SH})$ and other functional groups. ${ }^{21}$ Our study revealed that even when $\mathrm{Pb}$ content in kidney tissue was highly concentrated, IOLE pretreatment reduced the level markedly. This suggests that IOLE removes $\mathrm{Pb}$ from the kidney by chelating and/or increasing the clearance of $\mathrm{Pb}$ from the kidney. IOLE is rich in flavonoids that act as metal chelators due to the presence of multiple hydroxyl groups forming a coordination bond with $\mathrm{Pb}^{2+} \cdot{ }^{22}$ The mechanism governing the metal chelation property of IOLE is not yet clearly known; however, further investigation is needed.

Increases in kidney relative weight as observed in the current study reflected renal hypertrophy which is in accordance with previous studies. ${ }^{5}$ Furthermore, the decrease in body weight of $\mathrm{PbAc}$-intoxicated rats is also consistent with the previous report and supports the increase in the kidney relative weight noted here. Pretreatment of rats with IOLE

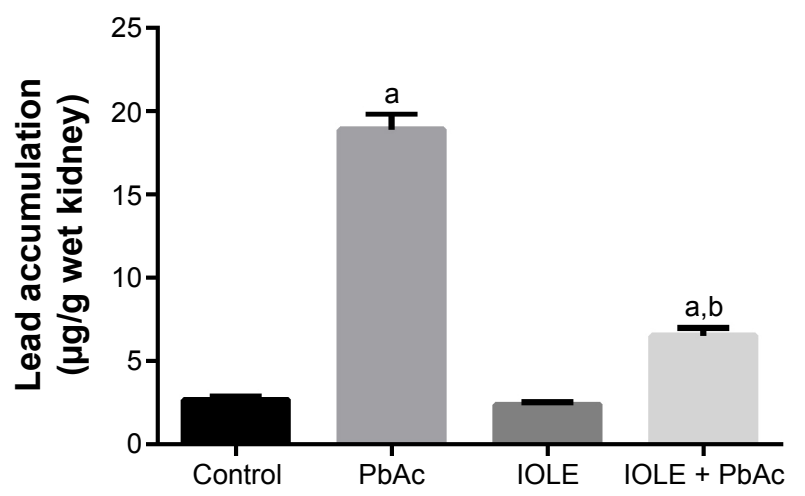

Figure 2 Ameliorative effects of IOLE on $\mathrm{Pb}$ accumulation in the kidney tissue of rats treated with $\mathrm{PbAc}$ for 5 days.

Notes: Values are given as mean $\pm \operatorname{SEM}(n=7)$. ${ }^{a} P<0.05$, significant change with respect to control; ${ }^{\mathrm{P}} \mathrm{P}<0.05$, significant change with respect to $\mathrm{PbAc}$ for Duncan's post hoc test.

Abbreviations: IOLE, Indigofera oblongifolia leaf extract; PbAc, lead acetate; SEM, standard error of the mean. prevented these observations. This suggests that IOLE has the ability to protect renal tissue from PbAc-induced renal hypertrophy.

The deleterious effects produced by $\mathrm{Pb}$ might be attributed to its ability to generate ROS which induce oxidative injury in the kidney by two separate, although related, pathways. ${ }^{20}$ The first pathway is the ability of $\mathrm{Pb}$ to enhance LPO, while the second pathway operates through the depletion of antioxidant reserve, whereby $\mathrm{Pb}$ interacts with sulfhydryl groups or metal cofactors in different enzymatic and nonenzymatic antioxidant molecules so as to induce a decline in antioxidant enzyme activity and in GSH. ${ }^{23}$

LPO is a prominent marker of oxidative stress as it is known to increase the production of epoxides, hydroperoxides, and MDA, all of which may interact with proteins, DNA, and RNA in the cell causing renal tissue damage. ${ }^{24}$ Here, IOLE has been shown to augment $\mathrm{Pb}$-induced nephrotoxicity through its considerable effect in reducing LPO production.

The increase in NO generation, evident in the current study, may contribute to the ability of $\mathrm{Pb}$ to enhance proinflammatory processes through the stimulation of NF- $\kappa B$, which in turn stimulates inducible NO synthase in macrophages. ${ }^{25} \mathrm{NF}-\kappa \mathrm{B}$ usually induces inflammation through inducible NO synthase/NO generation by controlling the transcriptional activation of the gene. ${ }^{26}$ The toxicity of NO increases greatly when it reacts with the superoxide radical, forming the highly reactive peroxynitrite anion $\left(\mathrm{ONOO}^{-}\right)$. Flavonoids, however, have been shown to directly scavenge NO. ${ }^{27}$ The presence of flavonoids could explain why IOLE was so effective in reducing NO.

GSH is a major, nonenzymatic antioxidant molecule, existing both intracellularly and extracellularly in living organisms, acting against xenobiotics and neutralizing ROS. The level of GSH in the body is, therefore, considered to be an important indicator of the antioxidative strength, and any disturbance in GSH can lead to serious consequences for the biological system. ${ }^{28}$ Oxidative stress is known to lower GSH content, ${ }^{29}$ and in the current experiment GSH content was indeed decreased in $\mathrm{PbAc}$-treated rats. This depletion in 

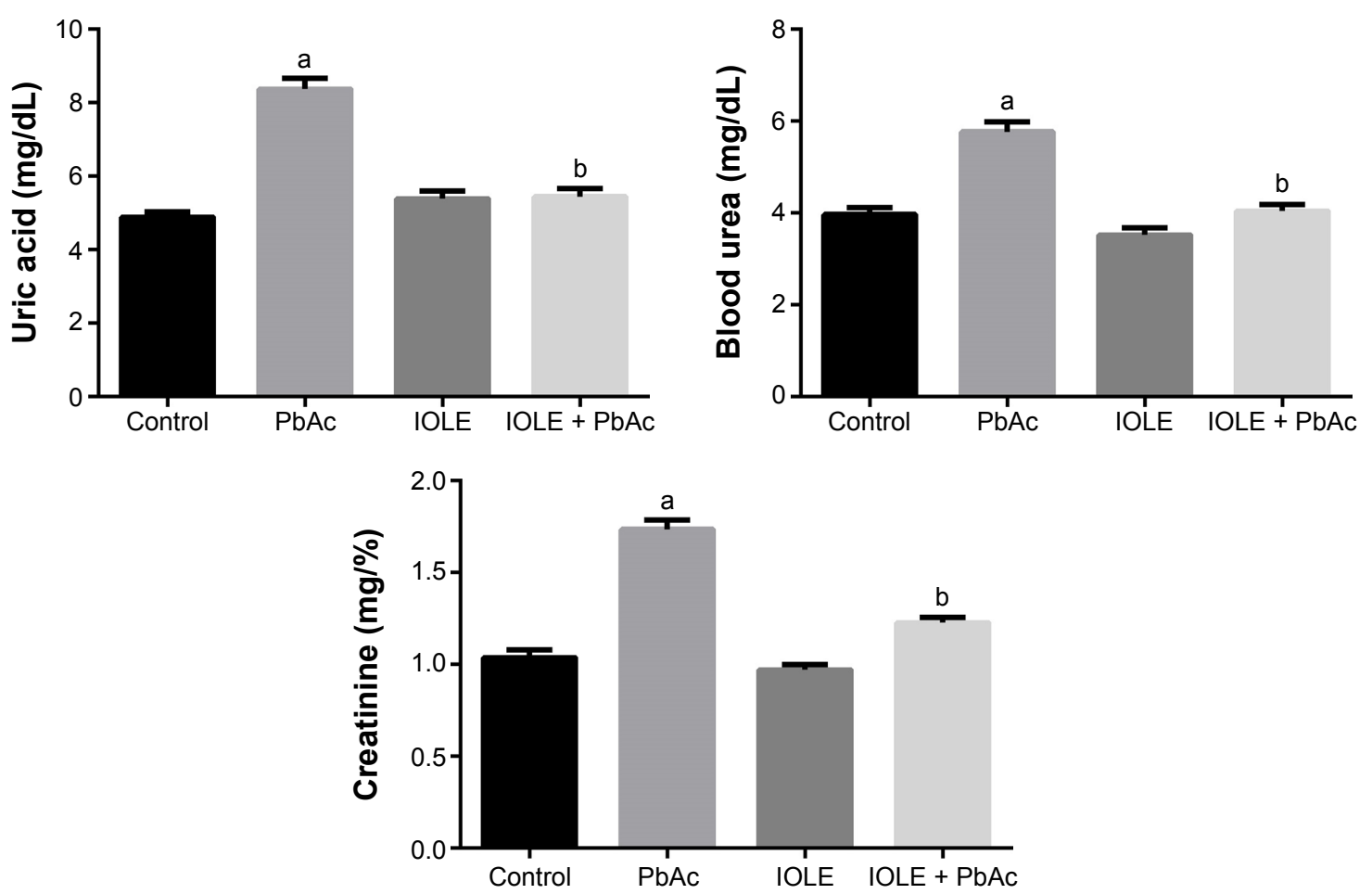

Figure 3 Ameliorative effects of IOLE pre-administration on ureic acid, urea, and creatinine in rats exposed to $\mathrm{PbAc}$ for 5 days.

Notes: Values are given as mean \pm SEM $(n=7)$. ${ }^{a} P<0.05$, significant change with respect to control; ${ }^{b} P<0.05$, significant change with respect to $P b A c$ for Duncan's post hoc test.

Abbreviations: IOLE, Indigofera oblongifolia leaf extract; PbAc, lead acetate; SEM, standard error of the mean.

GSH content might have contributed to the enhanced LPO. Furthermore, $\mathrm{Pb}$ inactivates GSH synthesis from cysteine via the $\gamma$-glutamyl cycle which further depresses the GSH content. ${ }^{20}$ This study found, however, that the GSH content in the kidneys of rats pretreated with IOLE was increased significantly suggesting that IOLE protects GSH from being depleted in kidney and thus maintains the antioxidant reserves in the kidney in the face of oxidative stress.

Diminished activities of antioxidant enzyme are frequently implicated under oxidative stress, and here, rats intoxicated with $\mathrm{PbAc}$ were reported to have significantly decreased levels of renal antioxidant enzymes. Among these enzymes, SOD catalyzes the conversion of superoxide anion-free radicals to $\mathrm{H}_{2} \mathrm{O}_{2}$ through a dismutation reaction, but $\mathrm{Pb}$, apart from targeting the sulfhydryl groups, appears also to interfere with the zinc ions that serve as cofactors for SOD, thereby inactivating it. CAT, meanwhile, is an important antioxidant enzyme having heme as the prosthetic group. $\mathrm{Pb}$ is known to decrease iron absorption and prevent heme biosynthesis. ${ }^{30}$ Similarly, $\mathrm{Pb}$ inactivates GPx and GR. Pretreatment with IOLE protected each of these enzymes from being altered, suggesting the regulatory role of IOLE on antioxidant enzymes.

Table 2 Oxidative stress marker levels and antioxidant enzyme activities in each group

\begin{tabular}{lllll}
\hline Parameters & Control group & PbAc group & IOLE group & IOLE + PbAc group \\
\hline LPO (nmol/mg protein) & $1.23 \pm 0.17$ & $1.91 \pm 0.1 I^{\mathrm{a}}$ & $1.16 \pm 0.12$ & $1.29 \pm 0.15^{\mathrm{b}}$ \\
NO $(\mu \mathrm{mol} / \mathrm{mg}$ protein) & $1.68 \pm 0.12$ & $2.23 \pm 0.16^{\mathrm{a}}$ & $1.48 \pm 0.14^{\mathrm{a}}$ & $1.8 \mathrm{I} \pm 0.13^{\mathrm{b}}$ \\
GSH (mmol/mg protein) & $0.32 \pm 0.02$ & $0.26 \pm 0.0 \mathrm{I}^{\mathrm{a}}$ & $0.39 \pm 0.02$ & $0.29 \pm 0.02^{\mathrm{b}}$ \\
SOD $(\mathrm{U} / \mathrm{mg}$ protein) & $923.5 \pm 83.6$ & $687.3 \pm 54.9^{\mathrm{a}}$ & $1,068.4 \pm 98.3^{\mathrm{a}}$ & $836.7 \pm 62.4^{\mathrm{b}}$ \\
CAT $(\mathrm{U} / \mathrm{mg}$ protein) & $0.4 \mathrm{I} \pm 0.02$ & $0.29 \pm 0.02^{\mathrm{a}}$ & $0.44 \pm 0.01$ & $0.38 \pm 0.02^{\mathrm{b}}$ \\
GPx $(\mu \mathrm{mol} / \mathrm{mg}$ protein) & $0.68 \pm 0.03$ & $0.5 \mathrm{I} \pm 0.03^{\mathrm{a}}$ & $0.72 \pm 0.04$ & $0.61 \pm 0.03^{\mathrm{b}}$ \\
GR $(\mu \mathrm{mol} / \mathrm{mg}$ protein) & $8.5 \pm 0.03$ & $4.8 \pm 0.02^{\mathrm{a}}$ & $8.9 \pm 0.05$ & $6.8 \pm 0.03^{\mathrm{a}, \mathrm{b}}$ \\
\hline
\end{tabular}

Notes: Values are given as mean \pm SEM ( $n=7)$. a $P<0.05$, significant change with respect to control; ${ }^{b}<0.05$, significant change with respect to $P b A c$ for Duncan's post hoc test.

Abbreviations: CAT, catalase; GPx, GSH peroxidase; GR, GSH reductase; GSH, glutathione; IOLE, Indigofera oblongifolia leaf extract; LPO, lipid peroxidation; NO, nitric oxide; $\mathrm{PbAc}$, lead acetate; $\mathrm{SEM}$, standard error of the mean; SOD, superoxide dismutase. 

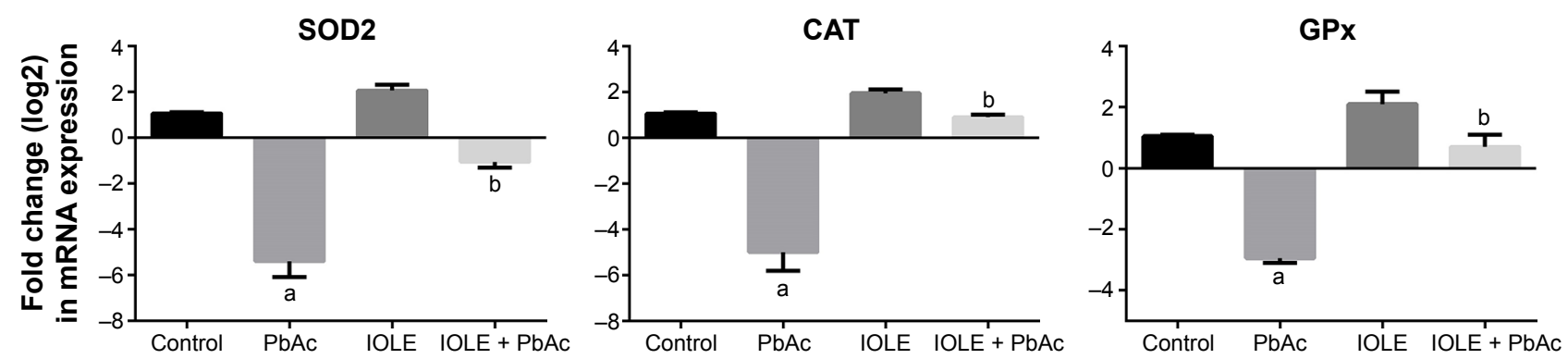

Figure 4 Ameliorative effects of IOLE pre-administration on mRNA expression of SOD2, CAT, and GPx genes in the kidney of rats exposed to PbAc for 5 days.

Notes: Values are given as mean \pm SEM $(n=7)$. ${ }^{a} P<0.05$, significant change with respect to control; ${ }^{b} P<0.05$, significant change with respect to $P b A c$ for $D$ uncan's post hoc test. Abbreviations: CAT, catalase; GPx, GSH peroxidase; GSH, glutathione; IOLE, Indigofera oblongifolia leaf extract; PbAc, lead acetate; SEM, standard error of the mean; SOD, superoxide dismutase.

In the current study, we have also examined the kidney function markers, finding PbAc-induced elevations in serum uric acid, urea, and creatinine that indicate kidney dysfunction. Pretreatment of rats with IOLE mitigated this elevation of negative kidney function markers. Overall, therefore, our results suggest that IOLE can prevent $\mathrm{Pb}$-induced renal damage and can help to preserve the normal function of the kidney.

The findings of the histological study support the abovementioned results, whether for the effect of $\mathrm{PbAc}$ or the preventive effects of the IOLE. The deleterious effect of $\mathrm{PbAc}$ on renal tissue, due to the oxidation actions, is a result of the overproduction of ROS, which induces cell injury and apoptosis. ${ }^{5}$ In order to have this effect, $\mathrm{Pb}$ is freely passed into the glomerulus and by endocytosis, and is reabsorbed in the proximal tubular cells. ${ }^{25}$ Once passed into the renal cell, $\mathrm{Pb}$ causes mitochondrial damage, uncoupling of the respiratory chain and cell death. ${ }^{31}$ Pretreatment of rats with IOLE serves to protect the kidney from this disruption by means of the
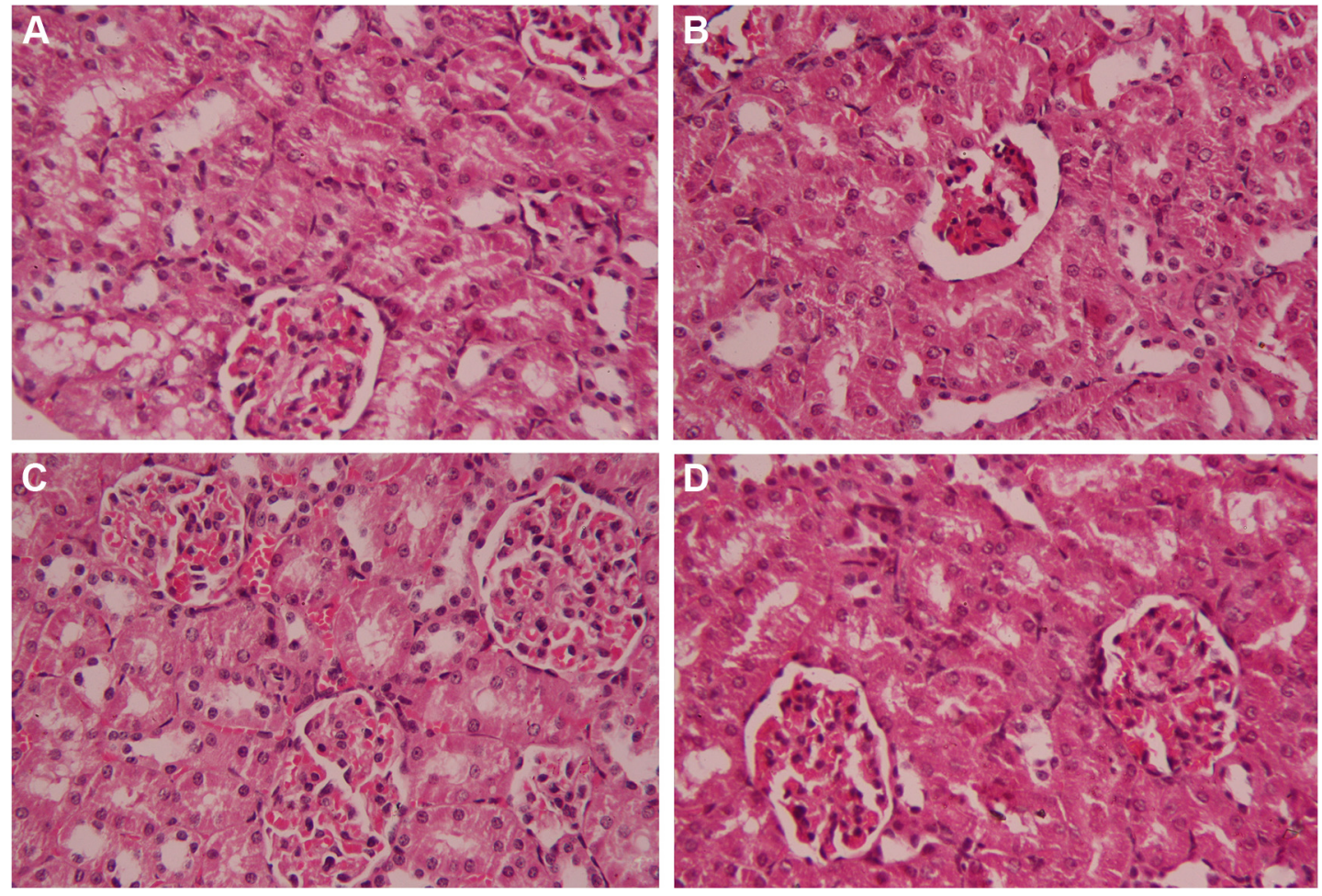

Figure 5 Light micrographs of the kidney.

Notes: (A) The normal histological feature of renal tubules and glomerulus in the control group. (B) Severe inflammation, extensive degeneration, cytoplasmic vacuolation, and congested glomeruli in the PbAc-treated group. (C) The normal histological structure of renal tubules and glomerulus in the IOLE group, similar to the control group. (D) The normal histological structure of renal tubules and glomerulus in the group IV, where the IOLE was pre-administered to PbAc. Some vaculated areas can be still seen, however (H\&E, 400x).

Abbreviations: H\&E, hematoxylin and eosin; IOLE, Indigofera oblongifolia leaf extract; PbAc, lead acetate. 

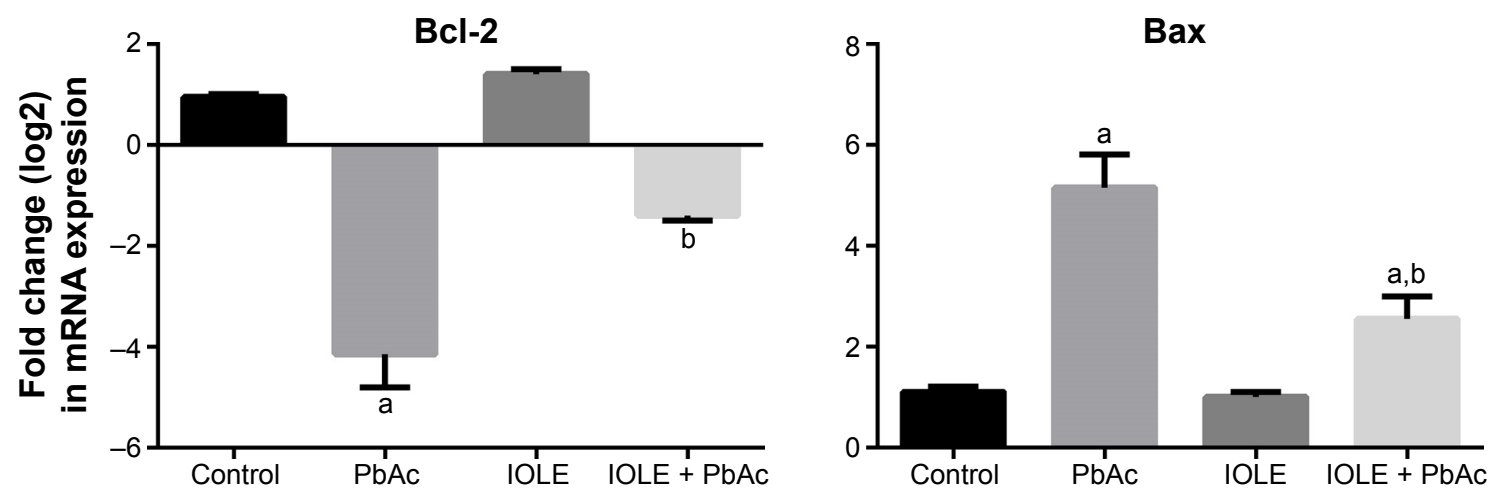

Figure 6 Ameliorative effects of IOLE pre-administration on mRNA expression of $\mathrm{Bcl}-2$ and $\mathrm{Bax}$ genes in the kidney of rats exposed to PbAc for 5 days.

Notes: Values are given as mean \pm SEM $(n=7)$. ${ }^{a} P<0.05$, significant change with respect to control; ${ }^{b}<0.05$, significant change with respect to PbAc for Duncan's post hoc test.

Abbreviations: Bax, Bcl-2-like protein 4; Bcl-2, B-cell lymphoma 2; IOLE, Indigofera oblongifolia leaf extract; PbAc, lead acetate; SEM, standard error of the mean.

various mechanisms discussed earlier. Our results, therefore, further strengthen the contention that IOLE can protect the kidney from PbAc-induced oxidative damage and can thus prevent PbAc-induced pathogenesis of the kidney.

In the current study, both the caspase-3 protein level and Bax mRNA level were significantly elevated in the renal tissue, while the Bcl-2 mRNA level was decreased significantly. These findings support those of Rong et al ${ }^{32}$ who suggested that the nephrotoxicity of $\mathrm{Pb}$ in vitro may be due to the acceleration of apoptosis related to the stimulation of the $\mathrm{NF}-\kappa \mathrm{B}$ and $\mathrm{p} 53$ genes and the depression of the $\mathrm{Bcl}-2$ gene. Furthermore, Agarwal et al ${ }^{13}$ have revealed that the activation of the caspase cascade and simultaneous extracellular signalregulated kinase dephosphorylation is the most significant operative pathway directly associated with apoptotic signals triggered by $\mathrm{PbAc}$ in vitro. Moreover, Yedjou et $\mathrm{al}^{34}$ found
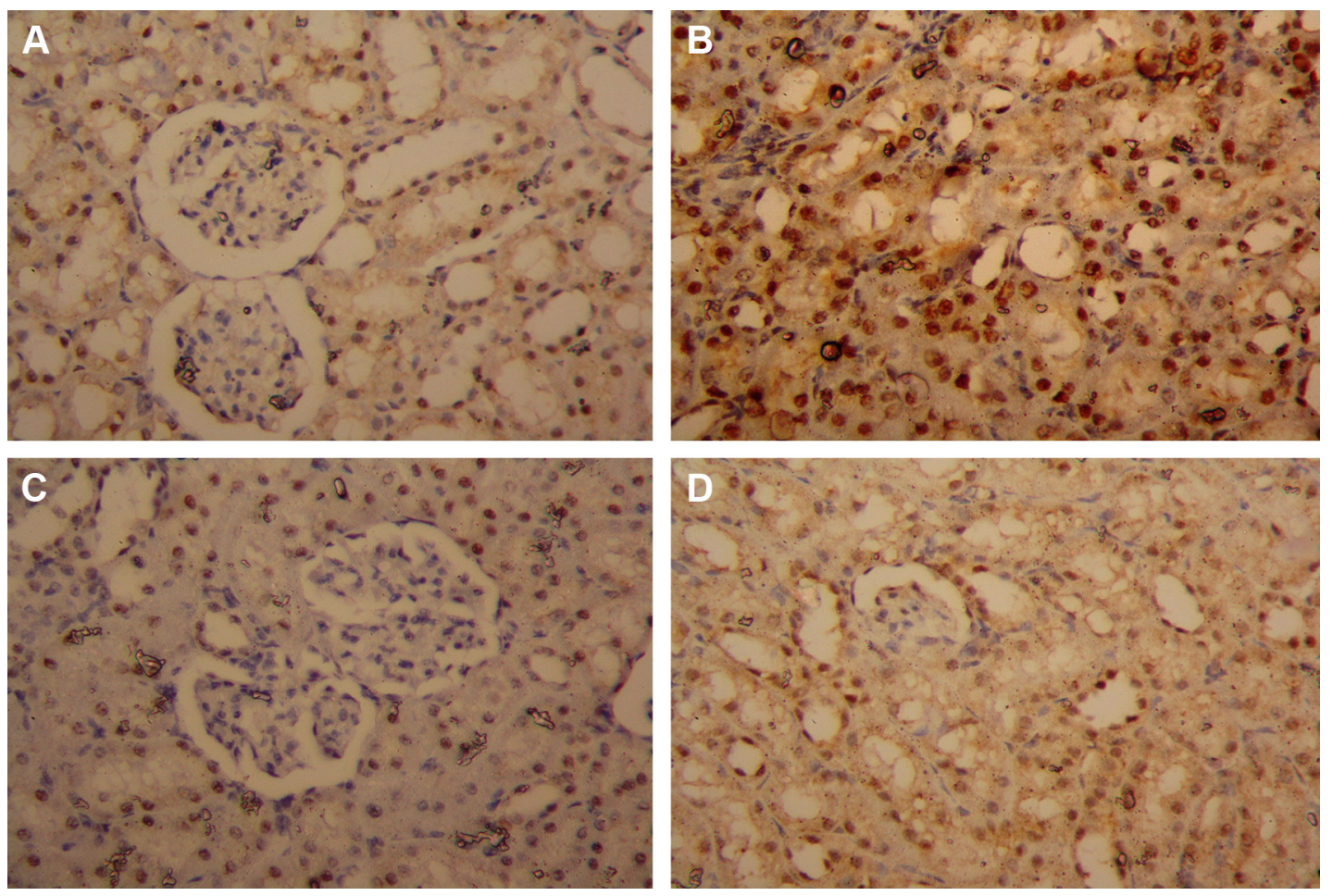

Figure 7 Changes in caspase- 3 expression in rat renal cells after the administration of IOLE and PbAc for 5 days.

Notes: (A) The normal histological feature of renal tubules and glomerulus in the control group with week immunostaining of caspase-3. (B) Alteration in the histological feature of renal tubules and glomerulus in the PbAc group with strong immunostaining of caspase-3. (C) The immunostaining of caspase-3 in the IOLE group, similar to that in the control group. (D) The immunostaining of caspase-3 in the group IV, where IOLE was pre-administered with $\mathrm{PbAc}$, similar to that in the control group (400x). Abbreviations: IOLE, Indigofera oblongifolia leaf extract; PbAc, lead acetate. 
that $\mathrm{Pb}$-induced apoptosis occurs, at least in part, via induction of phosphatidyl serine externalization and caspase-3 stimulation. Conversely, pretreatment with IOLE prevented apoptosis induction in the kidney. The protective effect of IOLE on kidney tissue is related to the inhibition of apoptosis, based on the ability of different phytochemicals to protect against stress-induced apoptosis.

In the current experiment, PbAc markedly increased caspase-3 expression indicating that $\mathrm{Pb}$ provokes cell death in the rat kidney. Interestingly, the administration of IOLE improved the kidney by decreasing the expression of caspase-3. This agrees with the work of Yuan et $\mathrm{al}^{35}$ who showed that the expression of caspase- 3 was distinctly elevated in rats treated with $\mathrm{PbAc}$. Caspase-3 plays a major role in the downstream part of mitochondrial pathway-mediated cell death, after dysfunction of the mitochondria and the release of cytochrome $\mathrm{c}$ into the cytoplasm. It is well documented that caspase- 3 activation occurs in $\mathrm{Pb}$-induced apoptosis in the reproductive system ${ }^{36}$ and apoptosis in human leukemia (HL-60) cells. ${ }^{37}$ Caspase- 3 is believed to be the final executor of apoptotic DNA damage. ${ }^{38}$

\section{Conclusion}

This study has shown that IOLE has significant antioxidant and anti-apoptotic activities and is able to effect a significant reversal of the $\mathrm{Pb}$-induced oxidative injury in kidney. The observed results could be due to the different polyphenols and flavonoids present in the extract. The current findings elucidate for the first time that the leaves extract of I. oblongifolia has anti-apoptotic and antioxidant properties in kidney tissue.

\section{Acknowledgment}

The authors extend their appreciation to the Deanship of Scientific Research at King Saud University for funding the work through the research group project no PRG-1436-02.

\section{Disclosure}

The authors report no conflicts of interest in this work.

\section{References}

1. El-Tantawy WH. Antioxidant effects of spirulina supplement against lead acetate-induced hepatic injury in rats. $J$ Tradit Complement Med. In press 2015.

2. Jia Q, Ha X, Yang Z, Hui L, Yang X. Oxidative stress: a possible mechanism for lead-induced apoptosis and nephrotoxicity. Toxicol Mech Methods. 2012;22(9):705-710.

3. Jabeen R, Tahir M, Waqas S. Teratogenic effects of lead acetate on kidney. J Ayub Med Coll Abbottabad. 2010;22(1):76-79.

4. El-Khishin IA, El-fakharany YM, Abdel Hamid OI. Role of garlic extract and silymarin compared to dimercaptosuccinic acid (DMSA) in treatment of lead induced nephropathy in adult male albino rats. Toxicol Rep. 2015;2:824-832.
5. Abdel Moneim AE, Dkhil MA, Al-Quraishy S. The protective effect of flaxseed oil on lead acetate-induced renal toxicity in rats. $J$ Hazard Mater. 2011;194:250-255.

6. Abdel-Moneim AE, Dkhil MA, Al-Quraishy S. The redox status in rats treated with flaxseed oil and lead-induced hepatotoxicity. Biol Trace Elem Res. 2011;143(1):457-467.

7. Sadek KM. Barley phenolic compounds impedes oxidative stress in lead acetate intoxicated rabbits. Oxid Antioxid Med Sci. 2012;1(2): $141-146$.

8. Abdou HM, Hassan MA. Protective role of omega-3 polyunsaturated fatty acid against lead acetate-induced toxicity in liver and kidney of female rats. Biomed Res Int. 2014;2014:435857.

9. Sharif A, Ahmed E, Malik A, et al. Lipoxygenase inhibitory constituents from Indigofera oblongifolia. Arch Pharm Res. 2005;28(7):761-764.

10. Shahjahan M, Vani G, Devi CS. Protective effect of Indigofera oblongifolia in CCl4-induced hepatotoxicity. J Med Food. 2005;8(2): 261-265.

11. Lubbad MY, Al-Quraishy S, Dkhil MA. Antimalarial and antioxidant activities of Indigofera oblongifolia on Plasmodium chabaudi-induced spleen tissue injury in mice. Parasitol Res. 2015;114(9):3431-3438.

12. Abdel Moneim AE. Flaxseed oil as a neuroprotective agent on lead acetate-induced monoamineric alterations and neurotoxicity in rats. Biol Trace Elem Res. 2012;148(3):363-370.

13. Lowry OH, Rosebrough NJ, Farr AL, Randall RJ. Protein measurement with the Folin phenol reagent. J Biol Chem. 1951;193(1):265-275.

14. Janero DR. Malondialdehyde and thiobarbituric acid-reactivity as diagnostic indices of lipid peroxidation and peroxidative tissue injury. Free Radic Biol Med. 1990;9(6):515-540.

15. Sun J, Zhang X, Broderick M, Fein H. Measurement of nitric oxide production in biological systems by using Griess reaction assay. Sensors. 2003;3(8):276.

16. Rahman I, Kode A, Biswas SK. Assay for quantitative determination of glutathione and glutathione disulfide levels using enzymatic recycling method. Nat Protoc. 2007;1(6):3159-3165.

17. Fisher AEO, Maxwell SC, Naughton DP. Catalase and superoxide dismutase mimics for the treatment of inflammatory diseases. Inorg Chem Commun. 2003;6(9):1205-1208.

18. Aebi H. Catalase in vitro. Methods Enzymol. 1984;105:121-126.

19. De Vega L, Fernandez RP, Mateo MC, Bustamante JB, Herrero AM, Munguira EB. Glutathione determination and a study of the activity of glutathione-peroxidase, glutathione-transferase, and glutathionereductase in renal transplants. Ren Fail. 2002;24(4):421-432.

20. Flora G, Gupta D, Tiwari A. Toxicity of lead: a review with recent updates. Interdiscip Toxicol. 2012;5(2):47-58.

21. Sharma SK, Goloubinoff P, Christen P. Heavy metal ions are potent inhibitors of protein folding. Biochem Biophys Res Commun. 2008; 372(2):341-345.

22. Kumar S, Pandey AK. Chemistry and biological activities of flavonoids: an overview. Scientific World J. 2013;2013:162750.

23. Flora SJ, Mittal M, Mehta A. Heavy metal induced oxidative stress \& its possible reversal by chelation therapy. Indian J Med Res. 2008;128(4): 501-523.

24. Kehrer JP, Klotz L-O. Free radicals and related reactive species as mediators of tissue injury and disease: implications for Health. Crit Rev Toxicol. 2015;45(9):765-798.

25. Reyes JL, Molina-Jijon E, Rodriguez-Munoz R, Bautista-Garcia P, Debray-Garcia Y, Namorado Mdel C. Tight junction proteins and oxidative stress in heavy metals-induced nephrotoxicity. Biomed Res Int. 2013; 2013:730789.

26. Lawrence $\mathrm{T}$. The nuclear factor NF-kappaB pathway in inflammation. Cold Spring Harb Perspect Biol. 2009;1(6):a001651.

27. Boora F, Chirisa E, Mukanganyama S. Evaluation of nitrite radical scavenging properties of selected Zimbabwean plant extracts and their phytoconstituents. J Food Process. 2014;2014:918018.

28. Pastore A, Federici G, Bertini E, Piemonte F. Analysis of glutathione: implication in redox and detoxification. Clin Chim Acta. 2003;333(1): 19-39. 
29. Bast A, Haenen GR. Interplay between lipoic acid and glutathione in the protection against microsomal lipid peroxidation. Biochim Biophys Acta. 1988;963(3):558-561.

30. Flora SJ, Flora G, Saxena G, Mishra M. Arsenic and lead induced free radical generation and their reversibility following chelation. Cell Mol Biol (Noisy-le-grand). 2007;53(1):26-47.

31. Wang L, Wang H, Hu M, Cao J, Chen D, Liu Z. Oxidative stress and apoptotic changes in primary cultures of rat proximal tubular cells exposed to lead. Arch Toxicol. 2009;83(5):417-427.

32. Rong J, Chang W, Lv L, Chen J. [Study on the roles of nuclear factorkappaB, p53 and Bcl-2 gene in lead acetate induced apoptosis in PC12 cells]. Wei Sheng Yan Jiu. 2008;37(3):262-263, 268. Chinese.

33. Agarwal S, Roy S, Ray A, Mazumder S, Bhattacharya S. Arsenic trioxide and lead acetate induce apoptosis in adult rat hepatic stem cells. Cell Biol Toxicol. 2009;25(4):403-413.
34. Yedjou CG, Milner JN, Howard CB, Tchounwou PB. Basic apoptotic mechanisms of lead toxicity in human leukemia (HL-60) cells. Int J Environ Res Public Health. 2010;7(5):2008-2017.

35. Yuan G, Dai S, Yin Z, et al. Sub-chronic lead and cadmium co-induce apoptosis protein expression in liver and kidney of rats. Int J Clin Exp Pathol. 2014;7(6):2905-2914.

36. Elgawish RAR, Abdelrazek HMA. Effects of lead acetate on testicular function and caspase-3 expression with respect to the protective effect of cinnamon in albino rats. Toxicol Rep. 2014;1:795-801.

37. Yedjou CG, Tchounwou HM, Tchounwou PB. DNA Damage, cell cycle arrest, and apoptosis induction caused by lead in human leukemia cells. Int J Environ Res Public Health. 2015;13(1):ijerh13010056.

38. Xu J, Ji LD, Xu LH. Lead-induced apoptosis in PC 12 cells: involvement of p53, Bcl-2 family and caspase-3. Toxicol Lett. 2006;166(2): $160-167$.

\section{Publish your work in this journal}

Drug Design, Development and Therapy is an international, peerreviewed open-access journal that spans the spectrum of drug design and development through to clinical applications. Clinical outcomes, patient safety, and programs for the development and effective, safe, and sustained use of medicines are a feature of the journal, which has also been accepted for indexing on PubMed Central. The manuscript management system is completely online and includes a very quick and fair peer-review system, which is all easy to use. Visit http://www.dovepress.com/testimonials.php to read real quotes from published authors.

Submit your manuscript here: http://www.dovepress.com/drug-design-development-and-therapy-journal 